\title{
Liability Implications of Physician-Directed Care Coordination
}

\author{
Mark A. Hall, JD \\ Ralph A. Peeples, JD ${ }^{1}$ \\ Richard W. Lord, Jr, $M D^{2}$ \\ 'Wake Forest University School of Law, \\ Winston-Salem, NC \\ ${ }^{2}$ Department of Family and Community \\ Medicine, Wake Forest University School of \\ Medicine, Winston-Salem, NC
}

Conflicts of interest: none reported

\section{CORRESPONDING AUTHOR}

Mark A. Hall, JD

Wake Forest University School of Law Winston-Salem, NC 27109-7206

mhall@law.wfu.edu

\begin{abstract}
PURPOSE Various public and private initiatives encourage physicians to coordinate care for patients who have multiple chronic conditions, but physicians may resist doing so for fear of liability. This article assesses the extent of liability risk.
\end{abstract}

METHODS This qualitative study combines legal research with key informant interviews. Relevant legal authorities were identified through literature searches in legal databases. In-depth interviews were conducted with a purposive sample of 16 key informants who have relevant expertise in malpractice insurance, risk management, or liability law. Additionally, 19 other participants with relevant experience in case management or managed care were briefly queried about their liability experience relating to care management.

RESULTS Some aspects of care coordination for patients with multiple chronic conditions hold potential for higher liability. Physicians coordinating care have a broader responsibility for patients with complex conditions who have a greater chance of poor outcomes. Care coordinators may be held to a higher standard of care by adopting best practices guidelines or by making medical decisions on issues that require specialized expertise. Other aspects, however, lower liability risk: elderly patients are less likely to sue, care coordination should improve outcomes, and the information systems that support enhanced care coordination target the major sources of medical error in primary care. On balance, the liability risks of care coordination are commensurate with other risks in primary care practice. Liability insurers indicated no reluctance to insure physicians who coordinate care for patients with multiple chronic conditions and no strong tendency to attribute higher risk to this role. Physicians who currently perform these or similar functions have not encountered demonstrably higher liability.

CONCLUSIONS Physicians' perceptions about the liability risks of coordinating care for patients with multiple chronic conditions do not match evidence about the factors actually driving liability. It appears from many informed sources that there is no strong basis for physicians who perform these functions to have serious concerns about liability; instead, care coordination done well may lower liability risks.

Ann Fam Med 2005;3:115-121. DOI: 10.1370/afm.288

\section{INTRODUCTION}

$\mathrm{V}$ arious public, private, and professional initiatives have focused on improving care for persons with chronic conditions seek to improve how physicians coordinate care among multiple specialties and across modes of treatment. ${ }^{1.7}$ For instance, the Future of Family Medicine report calls for a New Model of care that provides "a personal medical home" for each patient "that serves as the focal point through which" care is coordinated across multiple specialties and medical disciplines. ${ }^{8}$ This approach is consistent with a core aim of primary care to manage all aspects of a patient's care on an on-going basis, including care provided through specialty referrals, rather than focusing only on resolving the patient's immediate complaint. ${ }^{9-11}$ 
Several recent reports have found, however, that persons with multiple chronic conditions often encounter a complex and inefficient system of care as a result of inadequate care coordination. ${ }^{1,5}$ This population accounts for more than one half of medical spending, and they endure higher rates of avoidable complications and hospitalizations. ${ }^{4,12}$ Accordingly, improving care coordination for patients with multiple chronic conditions can substantially improve health outcomes and lower costs.

Many physicians may be reluctant to take on expanded care coordination. Possible reasons include the lack of adequate payment, the difficulty of creating an integrated clinical record, and an absence of appropriate information and decision support systems. ${ }^{1,13}$ In addition, many physicians may resist expanding care coordination responsibilities because so doing might increase their exposure to malpractice liability. ${ }^{14} \mathrm{~A}$ representative national sample of 1,238 practicing physicians $^{2}$ found that $49 \%$ listed legal liability as 1 of 2 main barriers to care coordination (Gerard F. Anderson, personal communication, November 15, 2004). This liability concern is understandable in the crisis atmosphere that surrounds medical malpractice, ${ }^{15,16}$ although further systematic analysis is required to determine how well-founded these possible concerns are and to shed more light on the exact dimensions of liability raised by care coordination.

A care-coordinating physician is responsible for reviewing the overall management of a patient's multiple conditions, encouraging compliance and preventive measures, making recommendations for additional referrals or changes in specialist management, and resolving possible conflicts in treatment recommendations from other physicians. A prototypical patient is on Medicare, has multiple chronic conditions, is seeing several specialists, and is taking more than a half dozen medications. The care coordinator would be a physician who is selected by the patient and who is probably (but not necessarily) the primary care physician. The physician would have access to integrated electronic medical records and would be supported by expert information systems, including evidence-based best practices guidelines. ${ }^{13}$ Functions of care coordinators might include establishing and monitoring a comprehensive treatment plan $_{i}$ recommending that a patient see fewer or different specialists; and resolving conflicts among specialists regarding medication, treatment, or patient behaviors.

This form of care coordination differs from other related practices known as disease management or case management. The principal difference is the role of the physician. In disease or case management the care coordination functions are contracted out to medi- cal personnel who usually are not physicians and who do not have a direct treatment relationship with the patient. ${ }^{17}$ Physician-directed care coordination centralizes care coordination functions with a treating physician. It is important for physicians who act as care coordinators to understand how this role affects their liability exposure. In this article, we explore these distinctive liability issues in depth.

\section{METHODS}

Our qualitative study relied on 2 primary sources of information: legal research, and key informant interviews. As more fully described in the Supplemental Appendix (which can be found online as supplemental data at http://www.annfammed.org/cgi/content/ full/3/2/115/DC1), we searched the legal and health policy literature for relevant articles and legal decisions. Search terms included variants of "malpractice liability" combined with one or more of the following: "care coordination," "disease management," "case management," "managed care," "capitation," "hospitalists," and "standard of care." Interviewed in depth were 16 persons with experience in either malpractice insurance, risk management, liability law, or disease management; 19 others were interviewed more briefly about liability aspects of care coordination or disease management. These persons were identified through 4 separate sources: their publications, membership in relevant professional organizations, referrals from other interview participants, and previous acquaintance with the authors. Participants were recruited through an iterative process in which additional informants were sought as long as new or different perspectives were being encountered, but recruitment ceased once a saturation point was reached in which informants were providing redundant information. This research was done according to a research protocol approved by the Wake Forest University Institutional Review Board, and all participants gave verbal consent and were promised anonymity.

We synthesized and analyzed the resulting information by using established qualitative ${ }^{18-22}$ and legal analytical techniques to assess both overall liability risk and the components of liability risk. Liability risk includes the risk of being named in a lawsuit and the likely size of settlements or judgments from such suits. Participants' views were triangulated by comparing views within and among different groups of informants, by comparing informed opinions with reported experiences, and by comparing interview sources with published legal sources, such as court decisions and legal treatises. The Supplemental Appendix provides greater detail about some aspects of these findings and analyses. 


\section{RESULTS}

\section{Similar Functions}

We identified 3 existing functions that are similar to care coordination: disease and case management, primary care gatekeeping, and hospital care provided by generalists. This section reports whether these functions have created liability concerns.

Disease management and case management are forms of care coordination routinely used by managed care insurers. ${ }^{17}$ There are differences between the 2 forms, but they share the aim of monitoring care for patients with serious chronic conditions to establish an optimal treatment plan, improve compliance, and reduce unnecessary hospitalizations. We found no indication that disease management or case management, as currently practiced by managed care entities, creates major liability risks, and 2 other research teams that have studied case management and disease management recently found no indication that liability is a major problem. ${ }^{17,23}$ The differences between care management by managed care entities and by physicians, however, could substantially alter the liability profile of care coordination.

Several expert informants noted that a closer example of physician-led care coordination is primary care gatekeeping as practiced in health maintenance organizations (HMOs) or under Medicaid. Consistent with another report ${ }^{24}$ we found no indication that $\mathrm{HMO}$ or Medicaid gatekeepers face substantially higher liability risks than do other primary care physicians. Gatekeeping, however, is not concentrated on chronically ill patients.

A number of key informants observed that primary care physicians provide care coordination for patients with more serious conditions when they serve as admitting or attending physicians for hospitalized patients by taking charge of the patient's overall care delivered by a team of specialists and hospital personnel. Despite the obvious liability risks, malpractice insurers said they do not vary rates within a specialty according to how often physicians admit hospital patients. Some malpractice insurers said, however, they charge as much as $50 \%$ more for hospitalists, ${ }^{25}$ who are physicians that specialize in coordinating inpatient care, whereas others said their rates are not higher than the physician's basic specialty, such as internal medicine. These experts noted that the increased risk for hospitalists was due not so much to the care supervision functions themselves, but to the unique problems created when hospitalized patients are transferred from one physician to another both when entering and when leaving the hospital. ${ }^{26,27}$ None of the key informants thought that the hospitalist example indicates a likelihood that outpatient care coordination would entail greater liability risks.

\section{Particular Risk Factors}

Key informants identified 3 sets of potential liability risk factors associated with care coordination for patients with multiple chronic conditions: the likely patient populations, the expanded professional responsibilities of a care-coordinating physician, and the use of information systems and best practices guidelines. In this section we analyze each of these components to assess qualitatively whether each tends to increase or decrease liability risk, or whether the component is neutral or indeterminate.

That patients with multiple chronic conditions are mostly elderly ${ }^{28}$ points to lower liability risk for several reasons. First, elderly patients are much less likely to sue their care providers, ${ }^{29-32}$ even though they are more likely to suffer medical injury. ${ }^{33}$ Moreover, if a suit is filed, elderly patients are less likely to generate high damage awards, because these awards often depend on life expectancy and earnings potential, both of which are substantially lower for the elderly. ${ }^{29,30,32}$

Key informants said that malpractice insurers do not use severity or illness complexity as a rating factor in assessing liability risk. Logically, some informants thought that those with chronic conditions probably do present a higher liability risk per patient, because the patients are more likely to have poor outcomes. No data were found to support this possibility, however, and other informants noted that the risk of poor outcomes is not necessarily disproportionate to the number of treatment encounters by chronically ill patients, because they also require more treatment and generate more reimbursement. Several participants also noted that patients with chronic conditions will have greater difficulty proving that poor outcomes are due to medical error rather than to their underlying condition. ${ }^{34}$ Furthermore, several professionals with experience in current forms of care management said that adding care coordination to physicians' responsibilities should reduce litigation risk by improving care and reducing adverse outcomes.

Consistent with this analysis are reports that the number of malpractice claims relating to diabetes is declining, ${ }^{35}$ despite a increasing prevalence of the disease and the multitude of complications that can result from mismanagement. One recent study found that, of 10 conditions that led to malpractice claims for negligent care in primary care, 8 were acute conditions, and diabetes ranked ninth (next to last) in frequency. ${ }^{36}$ Relative to the number of office visits associated with these same 10 medical conditions, diabetes produced the lowest rate of malpractice claims by far. Its relative risk for producing a negligence claim was less than one half (.42) that for office visits generally, and was 50 to 1,000 times less risky than most other condi- 
tions on the list of 10 , such as heart attack, cancer, and appendicitis. ${ }^{36}$

Another element of liability concern is physicians' sense that expanding care coordination requires them to assume a broader scope of responsibility for patient outcomes and quality of care. Physicians typically believe that referring patients to other physicians limits the scope of their responsibility, but care coordination potentially blurs this line by holding the coordinating physician responsible for monitoring the care delivered by other physicians. Most of our expert interviewees discounted this concern. Many participants questioned strongly the premise that physicians eliminate liability risks when they make referrals, because referring physicians remain responsible for some degree of follow-up based on the results of the referral. An enhanced carecoordinating role struck many experts as incurring only a modest increase in an already existing liability risk. Several participants thought that enhanced care coordination could lower liability risk by more explicitly defining and better supporting coordination functions, ${ }^{37}$ although some participants believed that increased scope of responsibility is a legitimate liability concern. Even so, increased responsibility may be offset by other components of care coordination that tend to lower liability risk.

A final factor that might affect liability is the use of best practices guidelines or integrated electronic medical records, computerized reminders, and other forms of information or decision support. ${ }^{13}$ In theory, using these tools might increase liability by holding coordinating physicians to a standard of care set by ideal best practices, and by making physicians responsible for the information in medical records of multiple physicians. In our interviews, however, the great majority of expert opinions were to the contrary. Participants believed the risks would not be serious; instead, care coordination would tend to decrease liability by improving outcomes and preventing medical errors. ${ }^{38}$ Additionally, informants thought that the increasing tendency is to hold physicians to more responsibilities for monitoring and coordinating care even if they do not officially undertake these functions, ${ }^{39}$ so providing the necessary information and systems support would reduce the opportunities for suit. ${ }^{40}$ Some were enthusiastic (it "would be a dream") about having decision support systems that would better document reasons for physicians' actions or inactions, since they viewed lack of good documentation as the largest source of liability. The only issue of concern that we detected related to the use of best practices guidelines, ${ }^{41,42}$ but no participant viewed best practices guidelines as a serious issue. . $^{38,43,44}$

Several participants noted that communication problems, inaccurate medical records, and other sys- tems problems are the root cause of most medical errors in outpatient settings; therefore, better information systems could greatly reduce opportunities for suit. ${ }^{38,45-47}$ For instance, one study of medical errors in primary care found that "informational or personal miscommunication" was the root cause of two thirds of medical errors, and that more than $90 \%$ of these communication errors "might be remedied by computers or other information systems." 48

On balance, the overall mix of liability factors arising from various aspects of care coordination do not point clearly toward greater liability risk. Instead, they appear to tip in favor of decreased liability. Treating patients with complex chronic conditions and adopting best practices guidelines were seen by a number of experts as potentially increasing liability, but not by a great deal. Other key informants did not believe these two factors increase liability, and many participants believed that care coordination could reduce liability by providing better information and decision support systems to catch and prevent the types of errors that are most common in outpatient care.

\section{Legal Doctrine}

The final area of inquiry is to consider how various branches of legal doctrine would view care coordination functions. This review is based primarily on an analysis of legal authorities, although some points are also confirmed by interviews, where noted.

There are ample opportunities, in theory, for finding physicians liable for negligence in performing care coordination functions, such as failing to refer patients or to communicate or follow up on test results. ${ }^{49-53}$ Such claims are not infrequent. A recent study of malpractice claims arising from primary care examined 15 years of claims data from the Physician Insurers Association of America. Of a total of 19 causes of negligent medical error in primary care, the second most common was "failure to supervise or monitor care" and the fifth was "failure/delay in referral." ${ }^{\text {"36 }}$ These indications, however, do not point toward an especially high level of liability exposure. Instead, they are consistent with comments made by key informants that the forms of liability inherent in care coordination simply "go with the territory" of medical practice.

Because enhanced care coordination is relatively new for physicians, it is not entirely clear from legal precedents what standard of care would be applied to determine negligence. Many key informants thought that, rather than a specialist standard, care coordination similar to the gatekeeping role in HMOs would become part of the general medical standard of care because core functions of coordination are not sufficiently different from what primary care physicians 
already do. Other participants, however, thought that enhanced care coordination might emerge as a separate area of practice or as a circumstance that alters the general standard of care. In this event, a coordinator would be judged by the standards of practice that are recognized by other coordinators treating similar kinds of patients. Legal experts confirmed our own analysis of legal authorities ${ }^{54,55}$ that professionally established standards promulgated for care coordination, as they have been for case managers, ${ }^{56}$ would strongly influence the legal standard of care for care coordinators. ${ }^{57}$

There is some basis for concern that certain aspects of care coordination might expose physicians to the standard of care practiced by physicians in specialties other than their own. For instance, if a coordinator offers medical advice on a matter requiring specialized expertise or makes a decision on an issue a specialist has also addressed, key informants thought that courts would likely hold the coordinator to the standard of skill and knowledge practiced in that specialty rather than the standard of a generalist. Key informants thought imposing a specialist standard of care is not likely if a coordinator does not make definitive medical decisions on issues that require specialized expertise. Instead, a generalist's or coordinator's standard of care would likely prevail when the coordinator is monitoring treatment adherence, making recommendations for additional referrals, keeping specialists informed, asking specialists to resolve any differences, or helping the patient understand his or her situation.

A final branch of potentially relevant legal doctrine is vicarious liability; lawyers might claim that coordinating physicians are automatically liable for mistakes of other physicians who treat the same patient by virtue of the physician's position and regardless of any fault or failure by the physician. Even so, key informants thought, consistent with our own review of legal authorities, that it is unlikely vicarious liability could be used against a coordinating physician for negligence committed by other physicians on the treatment team. Absent some business relationship among physicians, such as employment or partnership, the law generally holds each physician responsible only for his or her own conduct and does not hold one physician responsible for another's mistakes. ${ }^{49,54,58}$ For instance, a referring physician is not responsible for the mistakes of a specialist, nor is an attending physician responsible for mistakes of a covering physician. Even when one physician supervises another, the supervisor is not responsible vicariously; instead, the supervisor is responsible only for his or her own errors or failures to supervise with reasonable care.

In summary, none of the functions of care coordination pose new or especially threatening bases for liability under existing legal precedents. Medical law is adept at fashioning itself to fit varying and complex roles and relationships among physicians. Although some aspects of care coordination may fall within existing standards of care, and other aspects may evolve into a unique standard of care for coordinators, care coordination will not subject physicians to automatic or vicarious liability for mistakes of other physicians.

\section{CONCLUSIONS}

Others have noted that practicing physicians often have unfounded views about the factors that actually shape liability risk. ${ }^{59,60}$ This observation appears to be borne out here. A representative national sample of 1,238 practicing physicians ${ }^{2}$ found that $49 \%$ listed legal liability as 1 of the 2 main barriers to care coordination. Based on the collective experience and judgment of experts in medical liability, there does not appear to be any basis for physicians who perform care coordination to have serious concerns about liability; instead, care coordination may lower liability risks. Even though every medical function carries some liability risk, and care coordination is no exception, the extent of these risks appears to be broadly commensurate with other risks in primary care practice.

When physicians are asked to take on new roles or responsibilities, they understandably have some unease about their scope of responsibility. Focusing on potential malpractice liability is one way to express this unease. Other important innovations in health care delivery also have raised concerns about liability. For instance, managed care gatekeeping was expected to greatly increase liability, as was telemedicine, and there is ongoing concern about the use of practice guidelines After implementation, however, fears were found to far exceed reality in each of these areas. Whatever new liabilities might have arisen were not of a magnitude wholly different from those all physicians normally face. Nor were these liabilities sufficient to result in higher malpractice insurance premiums or to deter physicians from taking on these new roles. It appears from many informed sources that physicians who take a more active role in coordinating care for patients with multiple chronic conditions will meet the same or an even better fate in the legal system.

To read or post commentaries in response to this article, see it online at http://www.annfammed.org/cgi/content/full/3/2/115.

Key words: Primary care; case management; disease management; liability, legal

Submitted March 3, 2004; submitted, revised, July 1, 2004; accepted July 6, 2004. 
Funding support: Funding was provided by Johns Hopkins Bloomberg School of Public Health, through a grant from the Robert Wood Johnson Foundation to the Partnership for Solutions national program, directed by Gerard F. Anderson, PhD.

Acknowledgments: Janice Lawlor, MPH, and David Pope provided research assistance.

\section{References}

1. Anderson G, Knickman JR. Changing the chronic care system to meet people's needs. Health Aff (Millwood). 2001;20:146-160.

2. Anderson GF. Physician, public and policymaker perspectives on chronic conditions. Arch Intern Med. 2004;163:437-442.

3. Starfield B, Lemke KW, Bernhardt T, Foldes SS, Forrest CB, Weiner JP. Comorbidity: implications for the importance of primary care in 'case' management. Ann Fam Med. 2003;1:8-14.

4. Wagner EH, Austin BT, Van Korff M. Improving outcomes in chronic illness. Manag Care Q. 1996;4:511-544.

5. Institute of Medicine. Crossing the Quality Chasm. Washington, DC: National Academy Press; 2001.

6. Berenson R, Harris D. Using managed care tools in traditional medicare -- should we? could we? Law Contemp Prob. 2002;65:139-168.

7. Parrino T. Information technology and primary care at the VA: making a good thing better. Forum. October 13, 2003.

8. Future of Family Medicine Project Leadership Committee. The future of family medicine: a collaborative project of the family medicine community. Ann Fam Med. 2004;2(suppl_1):S3-S32.

9. Stange KC, Jaen CR, Flocke SA, Miller WL, Crabtree BF, Zyzanski SJ. The value of a family physician. J Fam Pract. 1998;46:363-368.

10. Starfield B. Primary Care: Balancing Health Needs, Services, and Technology. New York, NY: Oxford University Press; 1998.

11. Donaldson MS, Yordy KD, Lohr KN, Vanselow NA. Primary Care: America's Health in a New Era. Washington, DC: National Academy Press; 1996.

12. Nutting PA, Goodwin MA, Flocke SA, Zyzanski SJ, Stange KC. Continuity of primary care: to whom does it matter and when? Ann Fam Med. 2003;1:149-155.

13. Burton LC, Anderson GF, Kues IW. Using electronic health records to help coordinate care. Milbank Q. 2004;82:457-481.

14. Young RA. Concerns of the FFM report[eletter]. Available at: http:// www.annfammed.org/cgi/eletters/2/suppl_1/s3\#603, April 22, 2004.

15. US Department of Health and Human Services. Confronting the New Health Care Crisis. Washington, DC: US Department of Health and Human Services; 2002.

16. Mello MM, Studdert DM, Brennan TA. The new medical malpractice crisis. New Engl J Med. 2003;348:2281-2284.

17. Short A, Mays GP, Mittler J. Disease management: a leap of faith to lower-cost, higher-quality health care. Issue Brief No. 69. 2003. Center for Studying Health System Change.

18. Devers KJ. How will we know "good" qualitative research when we see it? Beginning the dialogue in health services research. Health Serv Res. 1999;34:1153-1188.

19. Borkan JM. Mixed methods studies: a foundation for primary care research. Ann Fam Med. 2004;2:4-6.

20. Hoff TJ, Witt LC. Exploring the use of qualitative methods in published health services and management research. Med Care Res Review. 2000;57:139-160.

21. Mays N, Pope C. Rigour and qualitative research. Br Med J. 1995;311:109-112.
22. Sofaer S. Qualitative methods: what are they and why use them? Health Serv Res. 1999;34:1101-1118.

23. Gillies RR, Shortell SM, Casalino L, Robinson JC, Rundall TG. How different is California? A comparison of U.S. physician organizations. Health Aff (Millwood). 2003;22:492-502.

24. Platt JB. Gatekeeper liability and managed care. Minn Med. 1996; 79:25-27.

25. Gesensway D. Hospitalists and the malpractice insurance crisis. Hospitalist. 2002;11-13.

26. Alpers A. Key legal principles for hospitalists. Am J Med. 2001;111 (9B):5S-9S.

27. Crane M. Malpractice: who's on the hook when a hospitalist discharges your patients? Med Econ Arch. 2002;1-8.

28. Chronic conditions: making the case for ongoing care. 2002. Partnership for Solutions. Available at: http://www. partnershipforsolutions.org/DMS/files/chronicbook2002.pdf.

29. Sager M, Voeks S, Drinka P, Langer E, Grimstad P. Do the elderly sue physicians? Arch Intern Med. 1990;150:1091-1093.

30. Kapp MB. The malpractice crisis: relevance for geriatrics. J Am Geriatr Soc. 1989;37:364-368.

31. Studdert DM, Thomas EJ, Burstin HR, Zbar BI, Orav EJ, Brennan TA. Negligent care and malpractice claiming behavior in Utah and Colorado. Med Care. 2000; 38:247-249.

32. Burstin HR, Johnson WG, Lipsitz SR, Brennan TA. Do the poor sue more? A case-control study of malpractice claims and socioeconomic status. JAMA. 1993;270:1697-1701.

33. Thomas EJ, Brennan TA. Incidence and types of preventable adverse events in elderly patients: population based review of medical records. BMJ. 2000; 320:741-747.

34. Kapp MB. Medical mistakes and older patients: admitting errors and improving care. JAGS. 2001;49:1361-1365.

35. Meredith V, Cook CB, Penman A. Use of the physician insurers association of America database as a surveillance tool for diabetes-related malpractice claims in the U.S. Diabetes Care. 1998;21:1096-1100.

36. Phillips JL Jr, Bartholomew JA, Dovey SM, Fryer GE Jr, Miyoshi TJ, Green LA. Learning from malpractice claims about negligent, adverse events in primary care in the United States. Qual Saf Health Care. 2004;13:121-126.

37. Thomson American Health Consultants Risk management principles can protect you from liability. Case Management Advisor. December 1, 2002:142.

38. Bates DW, Gawande AA. Improving safety with information technology. New Engl J Med. 2003;348:2526-2534.

39. Agency for Healthcare Policy and Research. An agenda for research in ambulatory patient safety. 2001. Available at: http://www.ahrq. gov/about/cpcr/ptsafety.

40. Sokol AJ, Molzen CJ. The changing standard of care in medicine: E-health, medical errors, and technology add new obstacles. J Legal Med. 2002;23:449-490.

41. Hyams AL, Brandenburg JA, Lipsitz SR, Shapiro DW, Brennan TA. Practice guidelines and malpractice litigation: a two-way street. Ann Intern Med. 1995;122:450-455.

42. Keffer JH. Guidelines and algorithms: perceptions of why and when they are successful and how to improve them. Clin Chem. 2001;47:1563-1572.

43. Goebel RH, Goebel MR. Clinical practice guidelines for pressure ulcer prevention can prevent malpractice lawsuits in older patients. J Wound Ostomy Continence Nurs. 1999;26:175-184.

44. Ransom SB, Studdert DM, Dombrowski MP, Mello MM, Brennan TA. Reduced medicolegal risk by compliance with obstetric clinical pathways: a case--control study. Obstet Gynecol. 2003;101:751-755. 
45. Dovey SM, Meyers DS, Phillips RL, et al. A preliminary taxonomy of medical errors in family practice. Qual Saf Health Care. 2002;11:238.

46. Dovey SM, Phillips JL Jr, Green LA, Fryer GE. Types of medical errors commonly reported by family physicians. Am Fam Phys. 2003;67:697.

47. Ely JW, Levinson W, Elder NC, Mainous AG3, Vinson DC. Perceived causes of family physicians' errors. J Fam Pract. 1995;40:337-344.

48. Woolf SH, Kuzel AJ, Dovey SM, Phillips RL Jr. Toxic cascades: a comprehensive way to think about medical errors. Am Family Physician. 2001;63:847

49. Dietz LH, Jacobs A, Lemming TL, Kennel JR. Physicians, Surgeons, and Other Healers. American Jurisprudence. St. Paul: West, 2003: 295-371.

50. Nold v. Binyon, 31 P.2d 274 (Kan. 2001).

51. Director JJ. Malpractice: physician's failure to advise patient to consult specialist or one qualified in a method of treatment which physician is not qualified to give. American Law Reports. 3d 1971;35:349.

52. Bass v. Barksdale, 671 S.W.2d 476 (Tenn. App. 1984).
53. Phillips v. Good Samaritan Hospital, 416 N.E.2d 646 (Ohio App. 1979).

54. Habeas WR. Liability of one physician or surgeon for malpractice of another. American Law Reports. 2d 1962;85:889.

55. Ward J. Medical residents: should they be held to a different standard of care? J Legal Med. 2001;22:283.

56. Case Management Society of America. Standards of Practice for Case Management. Little Rock, Ark: Case Management Society of America; 2002

57. Legal liability issues threaten case managers. Hosp Case Manag 2002;10:147-148.

58. Louisell DW, Williams H. Medical Malpractice. Newark, NJ: Matthew Bender; 2003.

59. Mello MM. Deterrence of medical errors: theory and evidence for malpractice reform. Texas Law Rev. 2002;80:1595-1636.

60. Sage W. Medical liability and patient safety. Health Aff (Millwood). 2003;22:26-36

\section{CHANGE-OF-ADDRESS FORM FAMILY MEDICINE}

Please complete this form and mail to the following address or fax to Annals Circulation at 913-906-6080:

Annals of Family Medicine, Circulation Department, 11400 Tomahawk Creek Pkwy, Leawood, KS 66211-2672

Check if member of sponsoring organization: $\square$ AAFP $\square$ ABFM $\square$ STFM $\square$ ADFM $\square$ AFMRD $\square$ NAPCRC

ID number from label on your journal cover $\ldots \ldots \ldots-\ldots$

OLD Information (Please print.)

Name

Company (if applicable)

Address (Street plus Apt or Ste)

City

Country

Telephone

E-Mail
NEW Information (Please print.)

Name

Company (if applicable)

Address (Street plus Apt or Ste)

City

State

Country Postal Code (9-digit ZIP for US)

Telephone $\quad$ Fax

E-Mail 